\title{
What Is the Impact of High-Resolution Manometry in the Functional Diagnostic Workup of Gastroesophageal Reflux Disease?
}

\author{
Jutta Keller \\ Department of Internal Medicine, Israelitic Hospital, University of Hamburg, Hamburg, Germany
}

\section{Keywords}

GERD · High-resolution manometry · Antireflux surgery · Fundoplication · Hiatus hernia

\section{Summary}

International guidelines agree that high-resolution esophageal manometry (HRM) is an integral part of the diagnostic evaluation of patients with refractory reflux symptoms and should be performed before antireflux surgery. Its most important goal is to explore differential diagnoses, in particular major esophageal motility disturbances, that may be responsible for symptoms. HRM additionally provides insights into all relevant pathomechanisms of gastroesophageal reflux disease (GERD): It can reveal important information on the morphology and function of the esophagogastric junction (EGJ), the presence of a hiatus hernia, transient lower esophageal sphincter relaxations, and dysmotility of the esophageal body. To obtain this information, a 3-step hierarchical system has been proposed for the algorithmic characterization of esophageal motor function. The first step is to investigate the morphology and contractility of the EGJ, the second to monitor esophageal body motor patterns in response to water swallows, and the third to determine the contraction reserve in patients with abnormal esophageal motor function using provocation tests. Observations made with HRM can not only explain the cause of symptoms in GERD patients but may also have the potential to direct specific treatment.

(c) 2018 S. Karger GmbH, Freiburg

\section{Introduction}

International guidelines agree that esophageal manometry is an integral part of the diagnostic evaluation of patients with refractory reflux symptoms and should be performed preoperatively in patients referred for antireflux surgery [1-4]. The most important rationale is to exclude differential diagnoses, in particular major esophageal motility disturbances such as achalasia, distal esophageal spasm, and hypercontractile esophagus that may be responsible for the symptoms [5]. The Chicago Classification has been established internationally for the classification of these esophageal motor disorders using high-resolution manometry (HRM) and for the identification of normal swallowing (fig. 1) [6].

Moreover, esophageal manometry has been suggested for the assessment of the competence of the esophagogastric junction (EGJ) as well as for the investigation of the clearance function of esophageal motility. However, efforts to identify patients with gastroesophageal reflux disease (GERD) based on findings obtained with conventional manometric techniques have been disappointing. It has been shown that pathological esophageal acid exposure is associated with reduced intra-abdominal length and pressure of the lower esophageal sphincter (LES) and ineffective peristalsis [7, 8]. However, there was a large overlap between GERD patients and healthy controls so that these findings have gained limited clinical relevance.

HRM with closely spaced sensors from the pharynx to the stomach (usually at $1-\mathrm{cm}$ intervals) greatly increases the spatial resolution compared to conventional manometry (using only 3-8 pressure ports) and may thereby overcome the limitations of the older technique. Furthermore, presentation of HRM data by pressure topography ('Clouse plots') reveals the functional anatomy of the EGJ in a visually intuitive manner [9].

Identifying metrics that provide an accurate assessment of the reflux barrier is an important factor in clinical manometric studies.

\section{KARGER}

() 2018 S. Karger GmbH, Freiburg 
Fig. 1. Normal liquid swallow on high-resolution esophageal manometry (HRM). Figure depicts the parameters used for analysis of single swallows according to the Chicago Classification [6].

\section{Integrated Relaxation \\ Pressure (IRP, $\mathrm{mm} \mathrm{Hg}$ ): Mean pressure during $4 \mathrm{~s}$ with maximal swallow-induced relaxation within $10 \mathrm{~s}$ after initiation of swallowing normal $<15 \mathrm{~mm} \mathrm{Hg}$ \\ Distal Contractile Integral (DCI, $\mathrm{mm} \mathrm{Hg}^{*}{ }^{*}{ }^{*} \mathrm{Cm}$ ): Amplitude $\mathrm{x}$ duration $\mathrm{x}$ length of distal es ophageal contraction, normal 450 to (5000-) $8000 \mathrm{~mm} \mathrm{Hg}{ }^{*} \mathrm{~cm}^{*} \mathrm{~s}$ \\ Contractile Deceleration Point (CDP): \\ Inflexion point in the contractile front propagation velocity in the distal es ophagus \\ Distal Latency (DL, s): \\ Interval between initiation of swallow and CDP, normal $>4,5 \mathrm{~s}$}

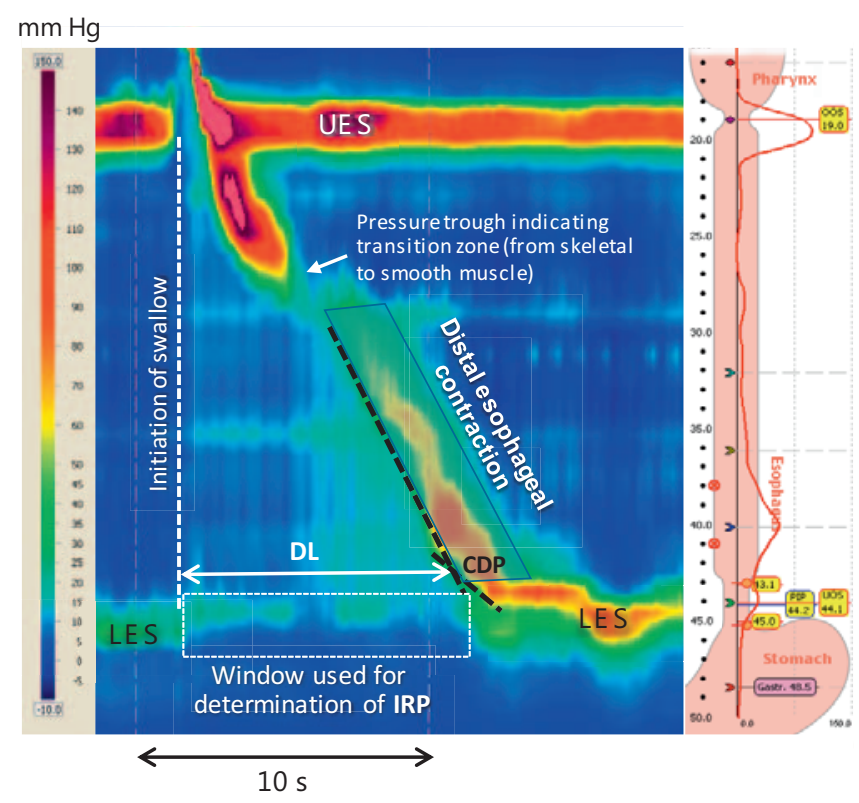

HRM measurements of esophageal motility and EGJ relaxation have been standardized by the Chicago Classification $[6,10,11]$, and a recent consensus paper of the International GERD Consensus Working Group specifically suggested a new classification for esophageal motor findings in GERD [12].

Based on these international recommendations, the current review will discuss the clinical relevance of HRM findings for the diagnosis and treatment of GERD. It is subdivided according to pathophysiological mechanisms that are thought to contribute to reflux disease and that are important to assess manometrically. These include altered morphology and decreased contractility of the EGJ, transient lower esophageal sphincter relaxations (TLESR), and esophageal body dysmotility. Additionally, the relevance of HRM for patients undergoing antireflux surgery will be discussed.

\section{EGJ Morphology and Hiatus Hernia}

EGJ morphology is defined by the interrelationship between the intrinsic LES and the crural diaphragm (CD) [12]. It has been characterized into 3 subtypes based on HRM [6] (fig. 2), where type 1 is equivalent to the physiological setting with superimposed LES and $\mathrm{CD}$; in type 2 , the pressure signal of the LES is separated from the pressure signal of the $\mathrm{CD}$ but both are less than $2-3 \mathrm{~cm}$ apart; in type 3 , the LES-CD separation exceeds $2-3 \mathrm{~cm}$. While older studies use a 2 -cm cut-off [6], the recent consensus paper by Gyawali et al. [12] defines a 3-cm cut-off to distinguish between types 2 and 3.

Type 2 and type 3 EGJ morphology is associated with reduced LES contractility which correlates with reflux severity [12, 13], and recent evidence suggests that not only EGJ type 3 but also type 2 represents a hiatus hernia [12]. Experts agree that evidence of a hiatus hernia on HRM should be reported, particularly in GERD patients. However, it is important to note that hiatus hernia size and reflux burden do not correlate in a linear fashion.

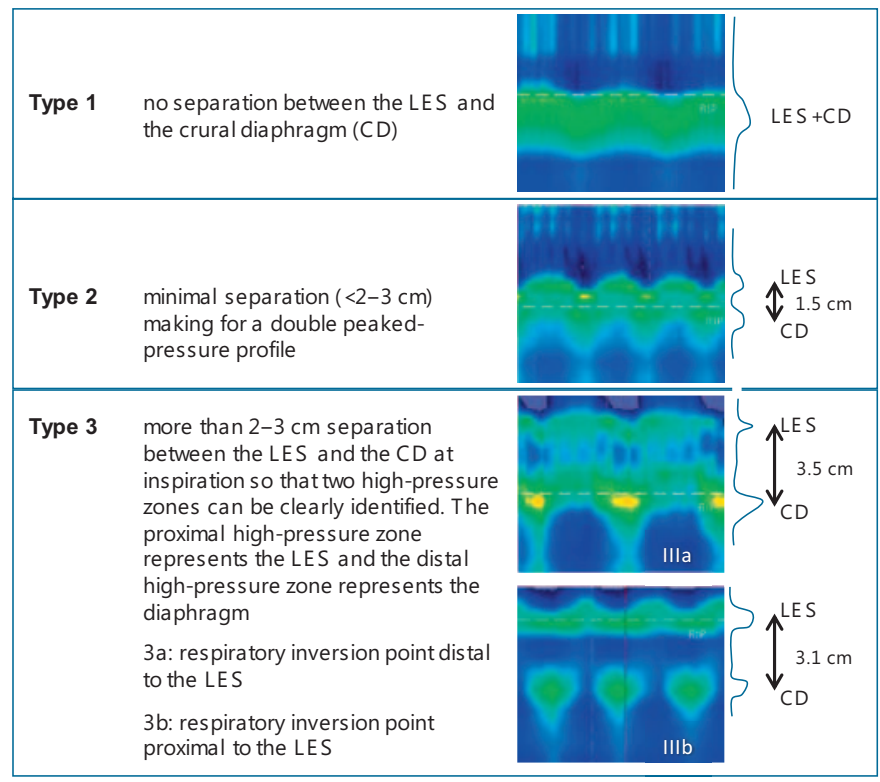

Fig. 2. Esophagogastric junction (EGJ) subtypes showing the physiological situation (EGJ type 1), small (EGJ type 2), and larger hiatus hernias (EGJ types $3 a$ and $3 b$ ) as displayed by high-resolution esophageal manometry (HRM). In hiatus hernia, there are 2 clearly separated high-pressure zones at the level of the cardia with the proximal one representing the lower esophageal sphincter (LES) and the distal one representing the diaphragm.

Using prolonged measurements, Bredenoord et al. [14] demonstrated an intermittent separation of the LES and the CD in GERD patients, which is associated with increased acidic and weakly acidic reflux. Moreover, they found that intermittent reduction of a small hiatal hernia (sliding hernia) is the rule rather than the exception. These findings suggest that EGJ pressure morphology dynamically varies with time and that spontaneous conversion among sphincter configurations occurs frequently [15]. 
Fig. 3. Assessment of esophagogastric junction (EGJ) contractility by $\mathbf{A}$ lower esophageal sphincter (LES) pressure integral (PI) and B EGJ contractile integral (CI). The LES-PI is determined by enclosing the domain of the LES area during a 10 -s period with the distal contractile integral (DCI) tool, setting the threshold isobaric contour (IBC) at $20 \mathrm{~mm} \mathrm{Hg}$ (referenced vs. atmospheric pressure). For assessment of the EGJ-CI, upper and lower margins of the EGJ are also enclosed in a DCI tool box for exactly 3 consecutive respiratory cycles. The threshold isobaric pressure is set at $2 \mathrm{~mm} \mathrm{Hg}$ (above gastric pressure). The resulting DCI value is then divided by the duration of the 3 respiratory cycles (in seconds).

Fig. 4. Assessment of esophagogastric junction (EGJ) contractility by total-EGJ contractile integral (CI). The total-EGJ-CI is determined by enclosing the EGJ area starting from the first and ending after the final water swallow (threshold $2 \mathrm{~mm} \mathrm{Hg}$ above gastric pressure). The resulting distal contractile integral (DCI) value is normalized by dividing by the duration of this interval.
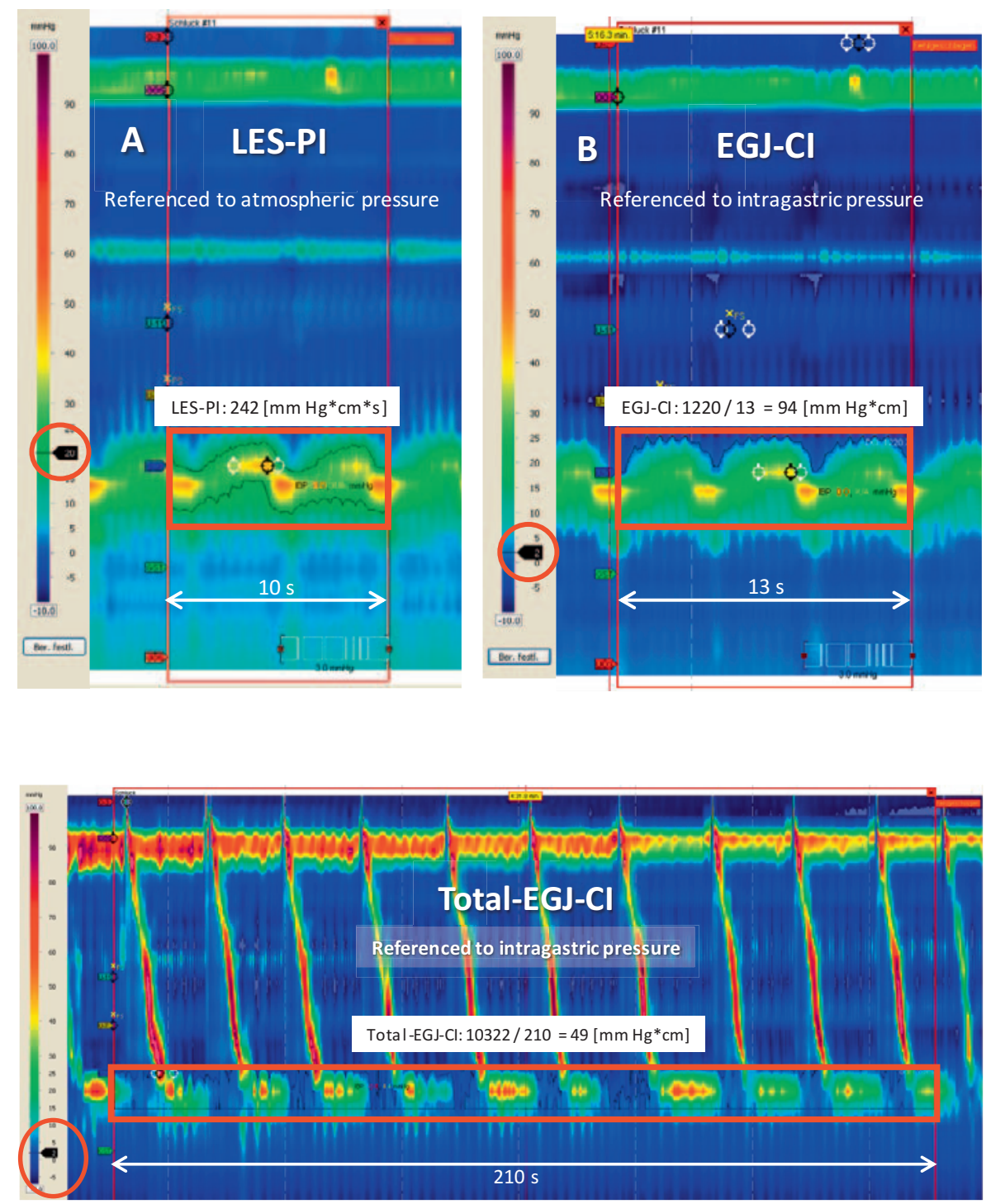

\section{EGJ Contractility}

Competence of the anti-reflux barrier is determined by both EGJ morphology and contractility. Thus, in addition to the classification of EGJ morphology as described above, the Chicago Classification v3.0 presents the LES pressure integral (LES-PI) and the EGJ contractile integral (EGJ-CI) as new HRM measures of EGJ contractility $[6,16,17]$. As shown in figure 3 , the LES-PI integrates EGJ pressure data from a 10-s window and is referenced to atmospheric pressure [16] (fig. 3A), and the EGJ-CI assesses EGJ contractility during 3 consecutive respiratory cycles and is referenced to intragastric pressure [17] (fig. 3B). Both parameters can be measured using the distal contractile integral (DCI) tool which is available in current HRM software packages. While the Chicago Classification v3.0 does not favor one over the other [6], more recent data has shown that the EGJ-CI is superior and allows better differentiation of patients with and without pathological reflux compared to LES-PI $[12,13]$. A newly developed modified param- eter, the so-called total-EGJ-CI, summarizes EGJ contractility over several minutes [13] (fig. 4). It predicts GERD even better than the EGJ-CI which is calculated during an approximately 30-s interval [13]. Importantly, pathological reflux was rare if the total-EGJ-CI was well within the normal range. These findings suggest that the value of HRM in GERD patients is not limited to ruling out major motility disorders. In addition to this important task, HRM could also more or less rule out pathological reflux as the cause of symptoms if EGJ contractility is normal [13]. Accordingly, the recent international consensus report clearly recommends the EGJ-CI but states that it is still an exploratory tool which needs further research [12].

Therefore, older parameters such as inspiratory, expiratory, or mean basal LES/EGJ tone may also be reported for clinical purposes. In any case, it is important to use a validated approach and to choose appropriate normal values because these differ depending on both the system and catheter used as well as the exact methodology chosen for evaluation of the EGJ. Using the Sierra/ 
Fig. 5. Transient lower esophageal sphincter relaxations (TLESRs) with an abrupt decrease in lower esophageal sphincter (LES) pressure to the level of intragastric pressure that is not triggered by swallowing. A TLESR occurs spontaneously on a background of stable and relatively high LES pressure. It is associated with diaphragmatic inhibition (black circles indicate where diaphragmatic contraction would have been expected) and with esophageal shortening (marked by white arrow). B Simultaneous impedance measurement demonstrates that the TLESR triggers gastroesophageal reflux.

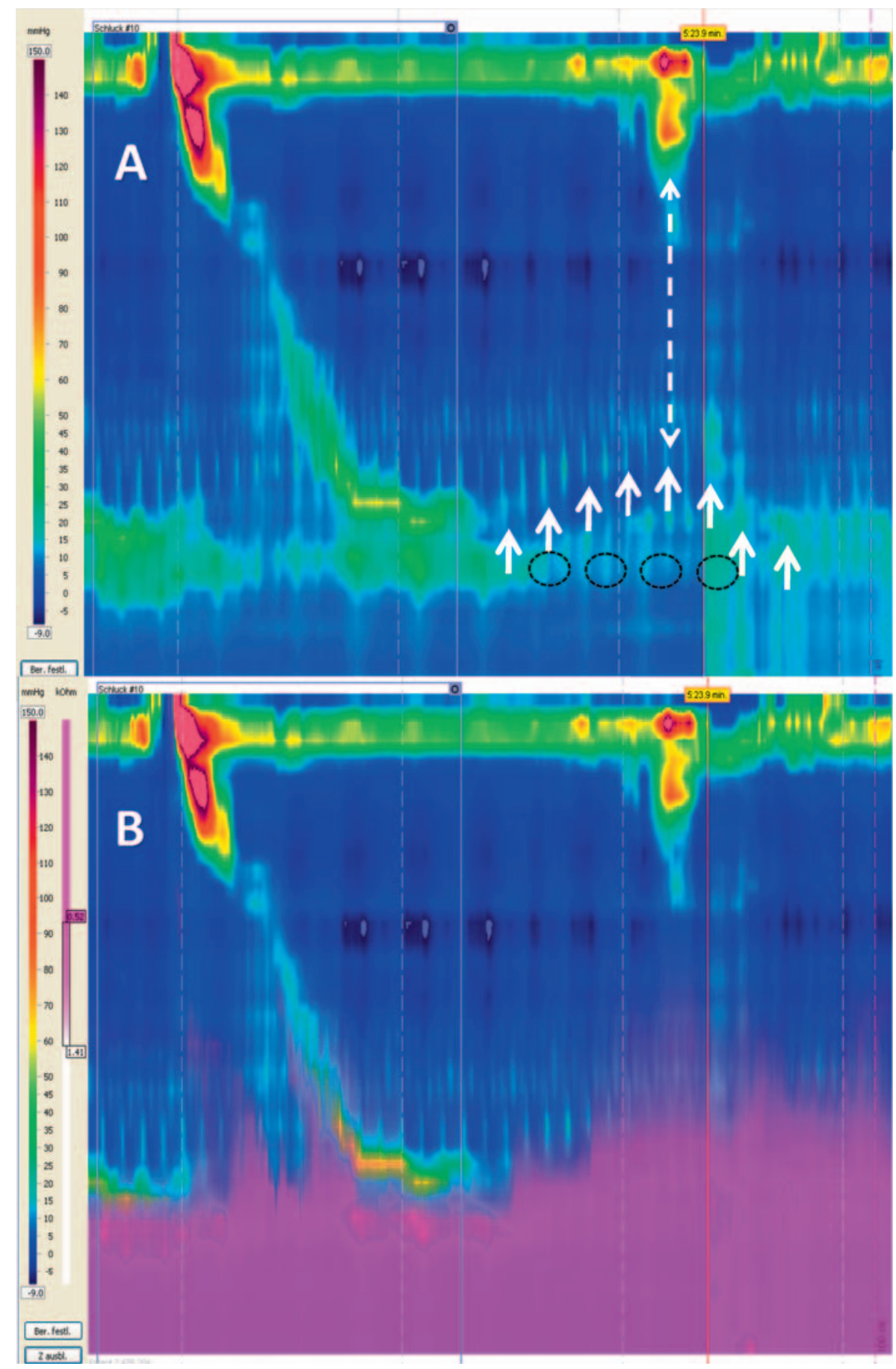

Medtronic system, we obtained the following normal values for EGJ parameters in a group of 64 healthy volunteers (median values, 5-95th percentile in parentheses) [13]:

- LES length: $2.8(1.6-5.3) \mathrm{cm}$

- Mean basal LES pressure: 21.3 (10.4-38.6) mm Hg

- Integrated relaxation pressure (IRP): $5.7(0.3-12.5) \mathrm{mm} \mathrm{Hg}$

- LES-PI: 104.6 (1.7-393.7) $\mathrm{mm} \mathrm{Hg/s/cm}$

- EGJ-CI $62.6(27.8-124.9) \mathrm{mm} \mathrm{Hg} / \mathrm{cm}$

- Total-EGJ-CI: 63.0 (38.5-117.3) $\mathrm{mm} \mathrm{Hg/cm}$.
Normal values for several systems and different parameters are reported by the Chicago Classification (appendix) [6] and in the recent international consensus report [12].

\section{Transient Lower Esophageal Sphincter Relaxations}

TLESRs represent an important pathomechanism for GERD. TLESRs are characterized by abrupt and prolonged decreases in LES pressure to the level of intragastric pressure in the absence of 
swallowing [18]. They may occur spontaneously on a background of relatively stable LES pressure (fig. 5A) or immediately after the completion of a normal swallow-induced LES relaxation. TLESRs are triggered by gastric distention and physiologically facilitate venting of swallowed air after meals (i.e., belching). Longitudinal smooth muscle contractions and esophageal shortening may be a key part of the mechanism that mediates TLESRs [19].

Compared with conventional manometry including the use of sleeve devices, HRM allows an easier detection of TLESRs and provides a higher level of inter-observer agreement. Diagnostic criteria proposed for TLERs using HRM include nadir pressure, relaxation duration, and percentage of relaxation [20]. HRM also allows identification of other criteria frequently associated with TLESRs such as diaphragmatic inhibition, esophageal shortening [21], and upper esophageal sphincter (UES) relaxation [22]. Therefore, experts believe that HRM should be considered as the gold standard for the detection of TLESRs. The combination with impedance measurement can detect reflux of liquid or air from the stomach and may further improve the validity of the investigation (fig. 5B).

Based on the detailed analysis of typical TLESRs and non-events by 17 international experts [23], the expert panel suggested to define a TLESR as a LES relaxation lasting for more than $10 \mathrm{~s}$ in the absence of swallowing within $4 \mathrm{~s}$ before and $2 \mathrm{~s}$ after the onset of LES relaxation associated with CD inhibition (fig. 5). Reflux on impedance was considered to be an important supportive criterion, and esophageal shortening, common cavity phenomenon, UES relaxation without swallowing, and secondary peristalsis were also considered to add to the diagnosis.

The proportion of reflux-associated TLESRs has consistently been shown to be greater in GERD patients compared with controls [24-26]. In normal subjects and patients with mild to moderate reflux disease, the majority of reflux episodes occur during TLESRs with almost all of the remainder occurring during swallow-induced LES relaxation associated with failed or incomplete primary peristalsis [18]. In patients with more severe disease, other mechanisms become more important (e.g., very low sphincter pressures, straining) [18]. This has been ascribed to the increasing prevalence of hiatus hernias and gross disruption of the reflux barrier in this group of patients $[4,15]$.

\section{Esophageal Dysmotility}

Impaired esophageal clearance prolongs the period during which aggressive gastric refluxate may damage the esophageal mucosa and, thus, plays a pathophysiological role in GERD [4]. In the absence of outflow obstruction, esophageal body peristalsis is the most important determinant of esophageal clearance (fig. 6).

However, studies using conventional techniques to investigate the association between dysmotility and esophageal clearance or mucosal disease gave inconclusive results [27]. It has been proposed that this may be due to inadequate spatial resolution of pressure sensors in conventional manometry and/or failure of the stimulus used in current protocols $(5-10 \mathrm{ml}$ water swallows) to elicit clinically relevant esophageal dysfunction [27]. In accordance with the investigation of the EGJ, HRM has been shown to be superior to conventional manometric techniques for the assessment of esophageal peristalsis, in particular if combined with impedance measurements (fig. 6) and if multiple water swallows and solid boluses are tested in addition to the conventional water swallowing protocol [6].

The most extreme degree of hypomotility to be detected by HRM consists of absent contractility (fig. 6B), which can be associated with elevated esophageal acid exposure. Ineffective esophageal motility (IEM), defined $s \geq 50 \%$ sequences with DCI below $450 \mathrm{~mm}$ $\mathrm{Hg} / \mathrm{cm} / \mathrm{s}$ and fragmented peristalsis where at least $50 \%$ of swallows have DCI within the normal range but with $\geq 5 \mathrm{~cm}$ breaks in the peristaltic contour, can also be associated with abnormal bolus transit and reflux $[6,12]$. The burden of reflux symptoms is correlated with the severity of peristaltic disturbances, with the highest burden in absent contractility [28]. Vice versa, it has been shown that esophageal hypomotility is common in GERD, particularly in patients with erosive disease or Barrett's esophagus [12, 29].

In contrast, patients with non-erosive reflux disease or reflux symptoms but physiologic esophageal acid exposure (reflux hypersensitivity, functional heartburn) may have relatively high distal esophageal contraction vigor [30]. Thus, while there are associations between severity of reflux burden and esophagitis with motor dysfunction, the interrelationship between these factors remains incompletely understood and requires further research [12].

\section{Provocation Tests}

The significance of HRM in the assessment of esophageal motor function in GERD can be improved by inclusion of provocation tests. They are performed by application of multiple rapid swallows (MRS), rapid drink challenge (RDC), or a test meal with solid boli. MRS refers to $52-\mathrm{ml}$ water swallows administered less than $4 \mathrm{~s}$ apart. RDC involves 'normal', uninterrupted drinking of a defined volume of water (100-200 ml). Repetitive swallowing induces deglutitive inhibition by hyperpolarization of esophageal smooth muscles. It thereby inhibits contraction in the esophageal body, and relaxes the LES [12]. Under physiological circumstances, the last swallow is often followed by a vigorous peristaltic contraction and a post-swallow LES after-contraction [31]. Both maneuvers generally test the overall integrity of the esophageal neuromuscular control, because a normal response requires intact inhibitory and excitatory central and peripheral neural pathways along with sufficient muscle reserve to produce a vigorous peristaltic contraction with or after the final swallow. They are therefore used to test the peristaltic reserve in patients with esophageal hypomotility [12]. The presence of a contraction reserve indicates augmentation of esophageal body contraction (using DCI) when compared to averaged DCI from wet swallows (MRS:wet swallow DCI ratio > 1). This is of clinical relevance because patients with inadequate response to MRS in the preoperative work-up appear to be prone to late postoperative dysphagia if they undergo antireflux surgery $[32,33]$. Since the post- 


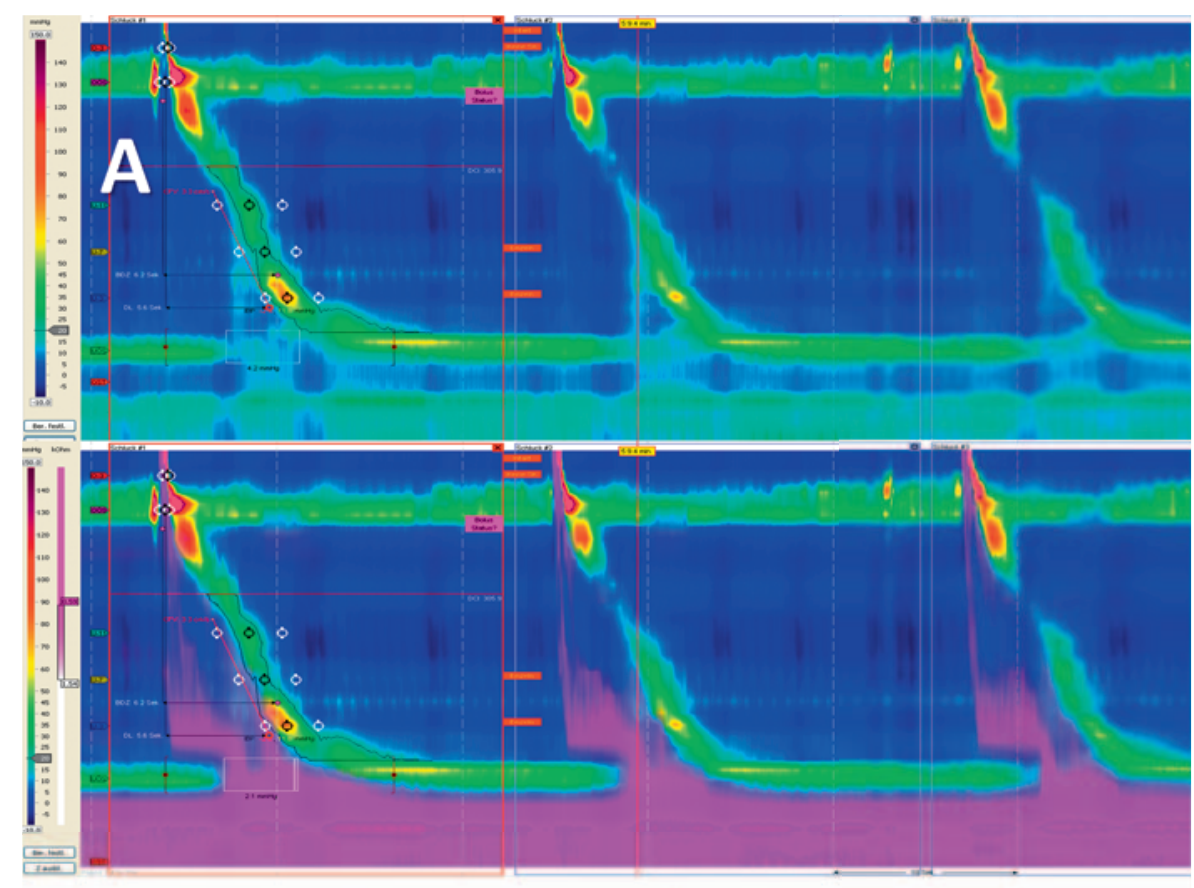

Fig. 6. A Ineffective esophageal motility and B absent peristalsis. As demonstrated by the lower panels showing results of combined impedance measurements, esophageal clearance of water swallows applied for high-resolution esophageal manometry (HRM) is still intact in this example of a patient with ineffective esophageal motility (IEM) (A), whereas in the patient with absent peristalsis, esophageal clearance is markedly impaired (B).

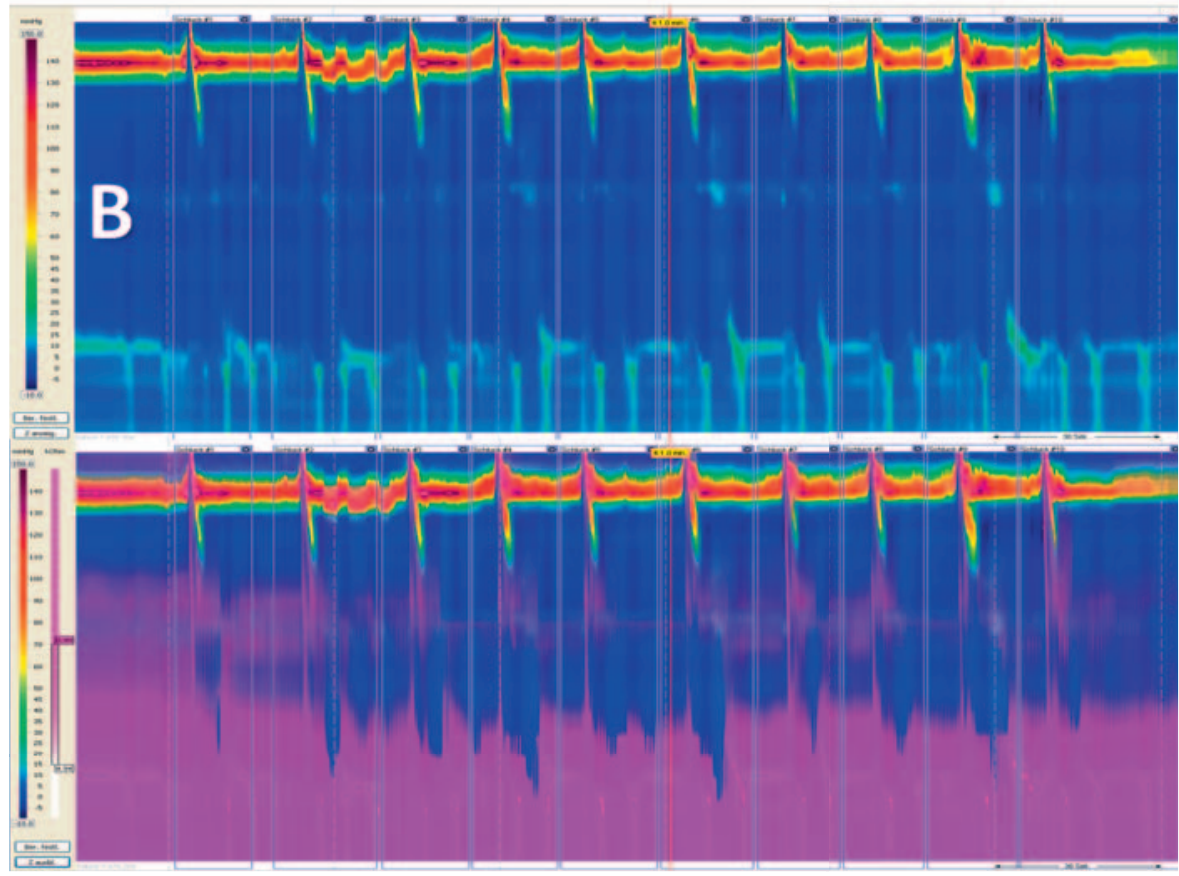

swallow contractile response is less reproducible with RDC, MRS is frequently favored for this purpose. On the other hand, RDC can serve to highlight EGJ outflow obstruction [34].

Motor response to solid swallows can also be used to assess the peristaltic reserve: If peristaltic vigor is normal in response to solid swallows, clinically relevant esophageal hypomotility is unlikely, even if weak or fragmented peristalsis has been diagnosed using water swallows. Moreover, similar to RDC, a test meal may reveal EGJ outflow obstruction which is not necessarily obvious during (single) water swallows [35]. This can be of particular importance in patients with unclear dysphagia following antireflux surgery [36].

\section{Antireflux Surgery}

The goal of antireflux surgery is to restore an anatomically and functionally competent gastroesophageal barrier. This includes correcting diaphragmatic crural defects, reestablishment of an intra-abdominal esophageal segment, and enhancement of the pressure and the length of the gastroesophageal high-pressure zone [4].

Fundoplication is safe and effective in a high proportion of patients; in about $10-20 \%$ of patients, symptoms will recur over $2-5$ years [4]. Moreover, a small proportion of patients may develop severe complications following antireflux surgery. Therefore, pa- 
tient selection for surgical treatment should be performed carefully, and manometric evaluation of esophageal motility is an integral part of the preoperative work-up.

It serves to [4]:

(1) identify patients with achalasia or other motility disorders as a cause of GERD-like symptoms,

(2) establish the adequacy of esophageal body contractile function which may influence the degree of fundoplication and/or the risk of new or persistent postoperative dysphagia, and

(3) confirm the manometric location of the upper border of the LES for accurate placement of catheter-based $\mathrm{pH}$ assessment.

Symptoms do not allow a reliable differentiation between GERD and esophageal transit disturbances. Indeed, even in many patients with newly diagnosed achalasia, reflux symptoms are reported as the predominant symptoms [5]. Vice versa, about $40 \%$ of patients with GERD may report dysphagia [37]. Therefore, HRM is mandatory before fundoplication to exclude alternative diagnoses. The concept of tailoring the fundoplication (partial vs. complete) based upon manometric findings of ineffective esophageal motility is debated [37]. However, information on esophageal contractility is helpful to prognosticate the outcome, if not to influence the selection of a partial fundoplication $[4,38,39]$.

Several studies additionally suggest that HRM is useful in the assessment of symptomatic patients following antireflux surgery [4, 14]: pre- and post-fundoplication EGJ dynamics and bolus transport have been assessed using concurrent HRM and fluoroscopy [40]. Postsurgically, EGJ lengths were significantly increased, the opening diameter decreased, and nadir EGJ relaxation pressures were significantly greater than prior to surgery. In addition, the intrabolus pressure was increased. Altered EGJ dynamics with increased resistance to flow are associated with prolonged transit times for liquid and solid bolus swallows, the degree of which is associated with postoperative dysphagia [40]. Accordingly, these parameters are useful in assessing persistent dysphagia post-fundoplication. The potential impact of RDC and solid swallows on the detection of postoperative outflow obstruction has been discussed above $[35,36]$.

HRM can differentiate between the effects of partial and $360^{\circ}$ fundoplication on EGJ pressure profiles [41]: less augmentation of the EGJ pressure profiles and greater frequency of TLESRs have been reported on HRM studies following partial fundoplication compared to complete fundoplication. Specific normal values developed in asymptomatic subjects with fundoplication show that HRM metrics for subjects after a Toupet fundoplication are similar to the normal values derived from healthy subjects used for the Chicago Classification [42]. By contrast, after Nissen fundoplication, a higher EGJ resting pressure and higher IRP are observed in asymptomatic subjects and this can be considered normal in the postoperative state. In addition, more vigorous contractions and less and smaller peristaltic breaks are normal after Nissen fundoplication [42].

\section{Conclusion}

Reflux symptoms are not only reported by the vast majority of patients referred for manometric studies, they frequently represent the dominant symptom and the reason for referral. In a subset of these patients, symptoms such as heartburn and regurgitation may be due to other diseases including major esophageal motility disturbances as defined by the Chicago Classification [6]. However, in addition to this essential differentiation, HRM also provides insights into all relevant pathomechanisms of GERD: HRM can reveal important information on the morphology and function of the EGJ, the presence of a hiatus hernia, TLESRs, and dysmotility of the esophageal body. To obtain this information, a 3-step hierarchical system is proposed for algorithmic characterization of esophageal motor function when HRM is performed in the setting of GERD, or when esophageal motor testing is undertaken to address esophageal peristaltic function prior to antireflux surgery [12]. Because of its importance for GERD severity, examination of the EGJ barrier is the first step in the evaluation of esophageal motor function in GERD. An impaired barrier can include a hypotensive EGJ, a hiatus hernia (type 2 or type 3 EGJ morphology), or both. If EGJ morphology and resting pressure are normal, TLESRs are implicated as the most likely mechanism underlying increased esophageal reflux burden. The next step is to assess esophageal body motor function, which affects esophageal clearance of refluxate. In most GERD patients, the esophageal body motor pattern is normal. Clearance function is most severely impaired in aperistalsis, followed by ineffective esophageal motility and fragmented peristalsis. If abnormal esophageal motor function is combined with abnormal EGJ barrier, esophageal reflux burden may be further enhanced [12]. The last step is to determine the contraction reserve in patients with abnormal esophageal motor function, preferentially using MRS. RDC and solid swallows can unmask EGJ outflow obstruction and are particularly useful in patients with persisting dysphagia following fundoplication. Thus, the observations made with HRM can not only explain the cause of symptoms in GERD patients, they may also have the potential to direct specific treatment.

\section{Disclosure Statement}

J.K. has received funds for research and honoraria for presentations from Covidien/Medtronic and Standard Instruments. 


\section{References}

1 Pandolfino JE, Kahrilas PJ: AGA technical review on the clinical use of esophageal manometry. Gastroenterology 2005;128:209-224.

2 Keller J, van der Voort I, Pehl C, et al.: Performance and interpretation of esophageal manometry: recommendations of the German Societies for Neurogastroenterology and Motility (DGNM), for Digestive and Metabolic Diseases (DGVS) and for General and Visceral Surgery (DGAV). Z Gastroenterol 2009;47:830-845.

3 Jobe BA, Richter JE, Hoppo T, et al.: Preoperative diagnostic workup before antireflux surgery: an evidence and experience-based consensus of the Esophageal Diagnostic Advisory Panel. J Am Coll Surg 2013;217: 586-597.

4 Keller JP, J.H.: Diagnosis and management of patients with reflux disease: role of high-resolution manometry?; in Fox MK, Kahrilas PJ, Pandolfino JE, Zerbib F (eds): Manual of High Resolution Esophageal Manometry. Bremen, UNI-MED, 2014.

5 Anderson SH, Yadegarfar G, Arastu MH, Anggiansah R, Anggiansah A: The relationship between gastrooesophageal reflux symptoms and achalasia. Eur J Gastroenterol Hepatol 2006;18:369-374.

6 Kahrilas PJ, Bredenoord AJ, Fox M, et al.: The Chicago Classification of esophageal motility disorders, v3.0. Neurogastroenterol Motil 2015;27:160-174.

7 O'Sullivan GC, DeMeester TR, Joelsson BE, et al.: In teraction of lower esophageal sphincter pressure and length of sphincter in the abdomen as determinants of gastroesophageal competence. Am J Surg 1982;143: 40-47.

8 Lee J, Anggiansah A, Anggiansah R, Young A, Wong T, Fox M: Effects of age on the gastroesophageal junction, esophageal motility, and reflux disease. Clin Gastroenterol Hepatol 2007;5:1392-1398.

9 Fox MR, Bredenoord AJ: Oesophageal high-resolution manometry: moving from research into clinical practice. Gut 2008; 57:405-423.

10 Kahrilas PJ, Ghosh SK, Pandolfino JE: Esophageal motility disorders in terms of pressure topography: the Chicago Classification. J Clin Gastroenterol 2008;42: 627-635.

11 Bredenoord AJ, Fox M, Kahrilas PJ, et al.: Chicago classification criteria of esophageal motility disorders defined in high resolution esophageal pressure topography. Neurogastroenterol Motil 2012;24(suppl 1):57-65.

12 Gyawali CP, Roman S, Bredenoord AJ, et al.; International GERD Consensus Working Group: Classification of esophageal motor findings in gastro-esophageal reflux disease: conclusions from an international consensus group. Neurogastroenterol Motil 2017;29:DOI: 10.1111/nmo.13104.

13 Jasper D, Freitas-Queiroz N, Hollenstein M, et al.: Prolonged measurement improves the assessment of the barrier function of the esophago-gastric junction by high-resolution manometry. Neurogastroenterol Motil 2017;29:DOI: 10.1111/nmo.12925.

14 Bredenoord AJ, Weusten BL, Timmer R, Smout AJ: Intermittent spatial separation of diaphragm and lower esophageal sphincter favors acidic and weakly acidic reflux. Gastroenterology 2006;130:334-340.
15 Kahrilas PJ, Peters JH: Evaluation of the esophagogastric junction using high resolution manometry and esophageal pressure topography. Neurogastroenterol Motil 2012;24(suppl 1):11-19.

16 Hoshino M, Sundaram A, Mittal SK: Role of the lower esophageal sphincter on acid exposure revisited with high-resolution manometry. J Am Coll Surg 2011;213: 743-750.

17 Nicodeme F, Pipa-Muniz M, Khanna K, Kahrilas PJ, Pandolfino JE: Quantifying esophagogastric junction contractility with a novel HRM topographic metric, the EGJ-Contractile Integral: normative values and preliminary evaluation in PPI non-responders. Neurogastroenterol Motil 2014;26:353-360.

18 Mittal RK, Holloway RH, Penagini R, Blackshaw LA, Dent J: Transient lower esophageal sphincter relaxation. Gastroenterology 1995;109:601-610.

19 Mittal RK, Karstens A, Leslie E, Babaei A, Bhargava V: Ambulatory high-resolution manometry, lower esophageal sphincter lift and transient lower esophageal sphincter relaxation. Neurogastroenterol Motil 2012; 24:40-46, e2.

20 Roman S, Zerbib F, Belhocine K, des Varannes SB, Mion F: High resolution manometry to detect transient lower oesophageal sphincter relaxations: diagnostic accuracy compared with perfused-sleeve manometry, and the definition of new detection criteria. Aliment Pharmacol Ther 2011;34:384-393.

21 Pandolfino JE, Zhang QG, Ghosh SK, Han A, Boniquit C, Kahrilas PJ: Transient lower esophageal sphincter relaxations and reflux: mechanistic analysis using concurrent fluoroscopy and high-resolution manometry. Gastroenterology 2006;131:1725-1733.

22 Pandolfino JE, Ghosh SK, Zhang Q, Han A, Kahrilas PJ: Upper sphincter function during transient lower oesophageal sphincter relaxation (tLOSR); it is mainly about microburps. Neurogastroenterol Motil 2007;19: 203-210.

23 Roman S, Holloway R, Keller J, et al.: Validation of criteria for the definition of transient lower esophageal sphincter relaxations using high-resolution manometry. Neurogastroenterol Motil 2017;29:DOI: 10.1111/ nmo. 12920 .

24 Sifrim D, Holloway R, Silny J, Tack J, Lerut A, Janssens $\mathrm{J}$ : Composition of the postprandial refluxate in patients with gastroesophageal reflux disease. Am J Gastroenterol 2001;96:647-655.

25 Trudgill NJ, Riley SA: Transient lower esophageal sphincter relaxations are no more frequent in patients with gastroesophageal reflux disease than in asymptomatic volunteers. Am J Gastroenterol 2001;96:25692574.

26 Ribolsi M, Holloway RH, Emerenziani S, Balestrieri P, Cicala M: Impedance-high resolution manometry analysis of patients with nonerosive reflux disease. Clin Gastroenterol Hepatol 2014;12:52-57.

27 Daum C, Sweis R, Kaufman E, et al.: Failure to respond to physiologic challenge characterizes esophageal motility in erosive gastro-esophageal reflux disease. Neurogastroenterol Motil 2011;23:517-e200.

28 Reddy CA, Patel A, Gyawali CP: Impact of symptom burden and health-related quality of life (HRQOL) on esophageal motor diagnoses. Neurogastroenterol Motil 2017;29:DOI: 10.1111/nmo.12970.
29 Savarino E, Gemignani L, Pohl D, et al.: Oesophagea motility and bolus transit abnormalities increase in parallel with the severity of gastro-oesophageal reflux disease. Aliment Pharmacol Ther 2011;34:476-486.

30 Kushnir VM, Prakash Gyawali C: High resolution manometry patterns distinguish acid sensitivity in noncardiac chest pain. Neurogastroenterol Motil 2011;23: 1066-1072.

31 Meyer GW, Gerhardt DC, Castell DO: Human esophageal response to rapid swallowing: muscle refractory period or neural inhibition? Am J Physiol 1981;241: G129-136.

32 Shaker A, Stoikes N, Drapekin J, Kushnir V, Brunt LM, Gyawali CP: Multiple rapid swallow responses during esophageal high-resolution manometry reflect esophageal body peristaltic reserve. Am J Gastroenterol 2013; 108:1706-1712.

33 Stoikes N, Drapekin J, Kushnir V, Shaker A, Brunt LM Gyawali CP: The value of multiple rapid swallows during preoperative esophageal manometry before laparoscopic antireflux surgery. Surg Endosc 2012;26:34013407.

34 Ang D, Hollenstein M, Misselwitz B, et al.: Rapid Drink Challenge in high-resolution manometry: an adjunctive test for detection of esophageal motility disorders. Neurogastroenterol Motil 2017;29:DOI: 10.1111/ nmo.12902.

35 Ang D, Misselwitz B, Hollenstein M, et al.: Diagnostic yield of high-resolution manometry with a solid test meal for clinically relevant, symptomatic oesophagea motility disorders: serial diagnostic study. Lancet Gastroenterol Hepatol 2017;2:654-661.

36 Wang YT, Tai LF, Yazaki E, et al.: Investigation of dysphagia after antireflux surgery by high-resolution manometry: impact of multiple water swallows and a solid test meal on diagnosis, management, and clinical outcome. Clin Gastroenterol Hepatol 2015;13:1575-1583.

37 Fibbe C, Layer P, Keller J, Strate U, Emmermann A Zornig C: Esophageal motility in reflux disease before and after fundoplication: a prospective, randomized, clinical, and manometric study. Gastroenterology 2001; 121:5-14.

38 Keller J, Fibbe C, Volke F, et al.: Inspection of the human stomach using remote-controlled capsule endoscopy: a feasibility study in healthy volunteers (with videos). Gastrointest Endosc 2011;73:22-28.

39 Brown SR, Gyawali CP, Melman L, et al.: Clinical outcomes of atypical extra-esophageal reflux symptoms following laparoscopic antireflux surgery. Surg Endosc 2011;25:3852-3858.

40 Scheffer RC, Samsom M, Haverkamp A, Oors J, Hebbard GS, Gooszen HG: Impaired bolus transit across the esophagogastric junction in postfundoplication dysphagia. Am J Gastroenterol 2005;100:1677-1684.

41 Van Lelyveld N, Scheffer R, Mundt M, Samsom M Partial gastric volumes and upper abdominal sensations in functional dyspeptic and GERD patients: a 3D ultrasonographic study. Am J Gastroenterol 2006;101 1845-1852.

42 Weijenborg PW, Savarino E, Kessing BF, et al.: Normal values of esophageal motility after antireflux surgery; a study using high-resolution manometry. Neurogastroenterol Motil 2015;27:929-935. 